\title{
Infection with Trypanosoma cruzi Tcll and Tcl in free-ranging population of lion tamarins (Leontopithecus spp): an 11-year follow-up
}

\author{
Cristiane Varella Lisboa, Rafael Veríssimo Monteiro, Andreia Fonseca Martins, \\ Samantha Cristina das Chagas Xavier, Valdirene dos Santos Lima, Ana Maria Jansen/+
}

Laboratório de Biologia de Tripanosomatídeos, Instituto Oswaldo Cruz-Fiocruz, Rio de Janeiro, RJ, Brasil

\begin{abstract}
Here, we present a review of the dataset resulting from the 11-years follow-up of Trypanosoma cruzi infection in free-ranging populations of Leontopithecus rosalia (golden lion tamarin) and Leontopithecus chrysomelas (goldenheaded lion tamarin) from distinct forest fragments in Atlantic Coastal Rainforest. Additionally, we present new data regarding T. cruzi infection of small mammals (rodents and marsupials) that live in the same areas as golden lion tamarins and characterisation at discrete typing unit (DTU) level of 77 of these isolates. DTU TcII was found to exclusively infect primates, while TcI infected Didelphis aurita and lion tamarins. The majority of $\mathrm{T}$. cruzi isolates derived from $\mathrm{L}$. rosalia were shown to be TcII (33 out 42) Nine T. cruzi isolates displayed a TcI profile. Golden-headed lion tamarins demonstrated to be excellent reservoirs of TcII, as 24 of $26 \mathrm{~T}$. cruzi isolates exhibited the TcII profile. We concluded the following: (i) the transmission cycle of $\mathrm{T}$. cruzi in a same host species and forest fragment is modified over time, (ii) the infectivity competence of the golden lion tamarin population fluctuates in waves that peak every other year and (iii) both golden and golden-headed lion tamarins are able to maintain long-lasting infections by TcII and TcI.
\end{abstract}

Key words: Trypanosoma cruzi - wild free-ranging mammals - Atlantic Rainforest reservoir host - sylvatic transmission cycle - discrete typing unit - DTU

Due to inherent difficulties, long-lasting studies on zoonotic parasite species of free-ranging wild mammal species are scarce; this is particularly the case of Trypanosoma cruzi, a highly heterogeneous, multihost and paninfective parasite taxon. The recognised genetic diversity of T. cruzi as well as its biological plasticity and huge distribution represent additional hindrances to our understanding of the variables that underlie the transmission cycle.

The six major genotypes or discrete typing units (DTUs), designated TcI to TcVI (Zingales et al. 2012) and TcBat (Marcili et al. 2009), that are recognised in the taxon have already been described in Brazilian biomes. However, the epidemiology of each of these DTUs is far from clear despite several attempts that have been made to recognise their mammalian hosts, reservoirs and distribution. Indeed, the six genotypes of $T$. cruzi occur in complex transmission cycles that may or may not overlap and should be understood as nonlinear and stochastic (Rocha et al. 2013).

The role of each mammalian host species in the maintenance and dispersion of $T$. cruzi depends primarily on the ability to maintain high parasitaemia (infectivity competence) so that its exclusively haematophagous

doi: 10.1590/0074-02760140400

Financial support: PAPES III/FIOCRUZ (0250250108), COLTRYP/

FIOCRUZ, Chagas EpiNet (FP7) (223034), CNPq (to CVL)

(311321/2010-0)

+ Corresponding author: jansen@ioc.fiocruz.br

Received 30 October 2014

Accepted 26 March 2015 vector (Hemiptera: Reduviidae) can acquire the parasite during feeding. The characteristic of maintaining longlasting parasitaemias varies depending on the combination of the T. cruzi DTU and the peculiarities of the mammalian host in addition to other aspects such as single or mixed DTU infection, overall host health status, concomitant infections with other parasite species, relative abundance of host species, contact rate with vectors, social behaviour (including migration patterns), immune response, climatic and seasonal variations and climate shifts such as the El Niño Southern Oscillation (ENSO) (Ashford 1996, Franke et al. 2002, McMichael 2003, Botto-Mahan et al. 2010). Apparently, different $T$. cruzi DTUs evolved distinct transmission strategies. TcI is predominant, while TcII, III, IV, V and VI have been described as occurring in much more restricted transmission cycles in the wild (Herrera et al. 2008, Lisboa et al. 2008, Miles et al. 2009, Zingales et al. 2012). The growing number of Tc (II-VI) isolates observed in sylvatic cycles from distinct regions, suggests that they are much more widespread than was recognised so far. This is particularly true for TcII, which was to infect a wide range of mammalian taxa including marsupials, rodents and carnivores, but always with a lower prevalence, particularly in comparison to TcI. The molecular characterisation of these isolates were conducted performing by mini-exon genotyping (Herrera et al. 2008, Lisboa et al. 2009), multilocus microsatellite typing and mitochondrial multilocus sequence typing (Ramírez et al. 2013).

One exception is the transmission cycle of TcII described in Atlantic Forest fragments in which a conservation program for the endemic tamarin species Leontopithecus rosalia (golden lion tamarin) from the Poço das Antas Biological Reserve (PDA), municipality of Silva Jardim, 
state of Rio de Janeiro, is maintained. In this forest fragment, there is a stable transmission cycle of $T$. cruzi that was originally characterised as Z2 in terms of zymodeme (Lisboa et al. 2000) and additionally as TcII based on a mini-exon gene (Lisboa et al. 2004). It has been demonstrated that tamarins are able to maintain stable T. cruzi infection with long lasting high parasitaemia, according to their high rates of positive haemocultures (HCs) (Lisboa et al. 2004). A similar scenario was observed in a distinct fragment of the Atlantic Forest located in the Northeast Region of Brazil [Una Biological Reserve (UNA), municipality of Una, state of Bahia], where another endemic tamarin species, Leontopithecus chrysomelas (golden-headed lion tamarin), also demonstrated a high $T$. cruzi infection rate with high parasitaemias as shown by the high rates of flagellate isolation in HCs (Monteiro et al. 2010).

Although several studies showing T. cruzi infection in wild mammalian host species have been published, studies indicating the persistence of $T$. cruzi infection in populations of wild free-ranging mammalian species are scarce (Alves et al. 2011, Rocha et al. 2013), particularly studies evaluating TcII in wild host.

Here, we had the unique opportunity to examine the same genetically homogeneous host population infected primarily by the same $T$. cruzi subpopulation (TcII) for more than a decade. We have conducted a revision of the dataset resulting from the study for $T$. cruzi infection in wild population of golden and golden-headed lion tama- rins from distinct fragments of Atlantic Coastal Rainforest during the period from 1995-2005. Additionally, we present new information about (i) T. cruzi infection pattern of small mammals (rodents and marsupials) examined in the golden lion tamarin living areas [reintroduction areas (RA)] and (ii) a characterisation at the DTU level of 77 isolates sampled over the 11 years of research in these fragments of the Atlantic Forest. The characterisation was performed based on the combination of three assays: large subunit (LSU) rDNA and mini-exon genotyping with polymerase chain reaction-restriction fragment length polymorphism (PCR-RFLP) using the following markers/restriction enzyme combinations 1F8/Alw211, heat shock protein 60 (HSP60)/EcoRV and glucose-6-phosphate isomerase (GPI)/HhaI according to the Rozas et al. (2007) and Lewis et al. (2009).

\section{MATERIALS AND METHODS}

Origin of T. cruzi isolates - The 77 T. cruzi isolates used in this study were deposited and have been maintained cryopreserved at Trypanosoma from Wild and Domestic Mammals and Vectors. Further details can be obtained from coltryp.fiocruz.br.

More information concerning the landscape physiognomy of PDA, RA and UNA may be found in the studies by Lisboa et al. (2004) and Monteiro et al. (2007). All study areas are demonstrated in Fig. 1.

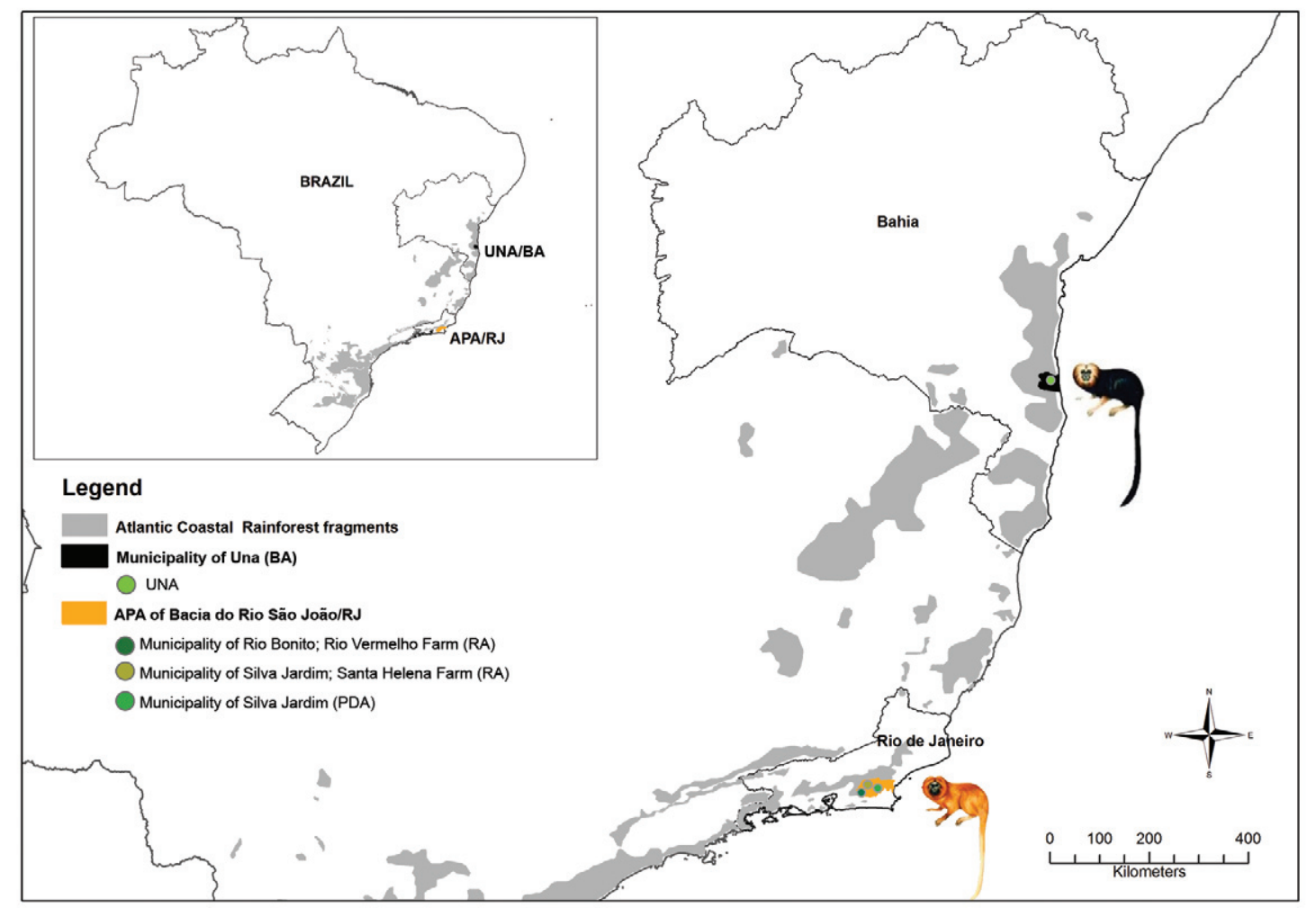

Fig. 1: collection sites of wild free-ranging Leontopithecus chrysomelas from Una Biological Reserve (UNA) [municipality of Una, state of Bahia (BA)] and Leontopithecus rosalia from Poço das Antas Biological Reserve (PDA) [municipality of Silva Jardim, state of Rio de Janeiro (RJ)] and reintroduction areas (RA) [Environmental Protection Area (APA) of Bacia do Rio São João (RJ)] in the Atlantic Coastal Rainforest of Brazil. 
T. cruzi infection patterns in small mammals (rodents and marsupials) examined in the golden lion tamarin living areas $(R A)$ - The Santa Helena Farm is one of 21 privately owned forest fragments that comprise the RA. These areas consist mainly of pasture, plantation and small forest fragments where wild tamarins are born and living (Beck et al. 1991).

Small wild mammals (rodents and marsupials) were noninjuriously captured using live traps $\left(\operatorname{Sherman}^{\circledR}, \mathrm{HB}\right.$ Sherman Traps, USA; Tomahawk ${ }^{\circledR}$, Tomahawk Live Traps, USA) baited with a mixture of banana, peanut butter, oat and bacon/sardines. Traps were set for five consecutive nights along linear transects placed on the ground at $10-\mathrm{m}$ intervals and alternating between trap type in three field expeditions (July 2003, January 2004 and August 2004). The trapped animals were taken to the field laboratory and, for each captured species, morphological identification, reproductive condition and age estimation (body weight for rodents and degree of tooth eruption for marsupials) were recorded. Total capture effort was 1,000 trapsnights, equally distributed among the three expeditions. We calculated the relative abundance of small mammals as the number of individuals of each species divided by the total number of individuals multiplied by 100 .

Parasitological tests were based on examination of fresh blood smears (microscopic analysis) and $\mathrm{HC}$, the latter performed as follows: $0.3 \mathrm{~mL}$ of blood from each animal was cultured in 2 tubes containing Novy-McNeal-Nicole medium with liver infusion tryptose overlay. Tubes were examined every 15 days up to five months.

For the detection of anti-T. cruzi IgG antibodies in sera, we used the indirect fluorescent antibody test (IFAT) as previously described by Camargo (1966). Rodent sera were tested with anti-rat IgG fluorescein isothiocyanate (FITC) (Sigma-Aldrich ${ }^{\circledR}$, USA). Didelphis were tested with specific intermediary anti-Didelphis antibodies raised in rabbits to visualise the reaction with an anti-rabbit IgG conjugate (FITC). The cut-off values adopted were 1:40 for marsupials and 1:10 for rodents, as described previously (Herrera et al. 2005, Roque et al. 2008). Prevalence of infection (HC and IFAT) was calculated based on the total of infected individuals divided by the total individuals sampled.

Ethics - Permission for the study and a license were obtained from the Brazilian government environmental agency, Brazilian Institute of Environment and Renewable Natural Resources (Biodiversity Authorization and Information System license 098/2002) and the study was endorsed by the Ethical Committee of Experimental Animal Research Committee/Oswaldo Cruz Foundation (CEUA L-015/04) in accordance with Brazilian regulations. Appropriate biosecurity techniques and individual protection equipment were used during all procedures involving sylvatic animals sample collecting and handling.

Evaluation of the data obtained during 11 years followup of T. cruzi infection in golden and golden-headed lion tamarins (1995-2005) - The data on T. cruzi infection were obtained from golden and golden-headed lion tamarins from three fragments: PDA, RA and UNA. The follow- ing parameters were tested: (i) annual tamarin population infection rates - total number of examined tamarins per year and number of animals testing positive for T. cruzi by IFAT and HC, respectively, (ii) serological conversion total number of tamarin testing positive according to IFAT each year and number of re-examined animals with negative IFAT, and (iii) prevalence of T. cruzi infection within each social group - total number of infected animals (IFAT and $\mathrm{HC}$ ) in each group in relation to the total number of primates examined per group. Only social groups monitored over three times were included in this analysis.

Molecular characterised of 77 T. cruzi isolates - Total genomic DNA was prepared from logarithmic phase cultures using standard phenol-chloroform protocols (Sambrook et al. 1989). Characterisation was carried out in three steps: (i) multiplex PCR amplification of the mini-exon gene following conditions described by Fernandes et al. (2001) for the identification of three DTU $T$. cruzi groups: \{Tc1 [TcI - 200 base pairs (bp)], Tc2 (TcII/ TcV/TcVI - 250 bp) and Zymodeme 3 (TcIII/ TcIV - 150 $\mathrm{bp})\}$ in addition to Trypanosoma rangeli (100 bp) or mixed infections were used; (ii) ribosomal RNA (rRNA) gene analysis - PCR amplification of the D7 divergent domain of the 24S $\alpha$ rRNA gene (LSU rDNA) was amplified as described by Brisse et al. (2001). Amplicons of 110-bp are characteristic of TcI/TcIII DTU, 125-bp of TcII/TcVI, 120 or 130-bp of TcIV and both 110 and 125 bp for TcV; (iii) PCR-RFLP analysis of the three target loci and restriction enzyme combinations: 1f8 gene (1f8/ Alw21I), HSP60/EcoRV and GPI/HhaI genes was accessed using the methodology described by Rozas et al. (2007) and Lewis et al. (2009). Each reaction included a negative control and positive control samples from those T. cruzi strains representing the DTUs to be typed: $1 f 8$ TcI/II, HSP60 - TcI/III/IV and GPI - TcI/III.

\section{RESULTS}

This long lasting study of T. cruzi infection in freeranging tamarins in the Atlantic Rainforest showed that: (i) the enzootical picture of the transmission cycle of $T$. cruzi in a given forest fragment may modify over time, (ii) the distinct enzootical scenarios with the same T. cru$z i$ DTUTcII were observed in single but proximate forest fragments of the Atlantic Rainforest and (iii) the high parasitaemia by T. cruzi as expressed by positive HCs occurred in waves of approximately two years (PDA).

T. cruzi infection pattern in rodents and marsupial examined in golden lion tamarin living areas (RA) The diversity of rodent and marsupial species was low since only five species, Akodon sp., Didelphis aurita, Nectomys squamipes, Oryzomys sp. and Trynomys sp. were captured in the RA (Santa Helena Farm) (Table I). T. cruzi infection detected by IFAT was observed in $N$. squamipes $(15 / 18-83 \%)$, D. aurita $(17 / 47$ - 36\%) and Akodon sp. $(3 / 20-15 \%)$, but the parasite was isolated only from two out of 17 big-eared opossums (D. aurita) that also exhibited positive serological IFAT (Table I). No patent parasitaemia was observed in fresh blood smears (microscopic analysis). 


\section{TABLE I}

Prevalence of infection by Trypanosoma cruzi in rodents and marsupials of the Santa Helena Farm (reintroduction area) in the Atlantic Coastal Rainforest of state of Rio de Janeiro, Brazil

\begin{tabular}{|c|c|c|c|}
\hline Order of mammal & Species & $\begin{array}{c}\text { Positive IFAT/ } \\
\text { examined animals } \\
\text { n/n (\%) }\end{array}$ & $\begin{array}{c}\text { Positive } \mathrm{HC} / \\
\text { positive IFAT } \\
\mathrm{n} / \mathrm{n}(\%)\end{array}$ \\
\hline Didelphimorphia & Didelphis aurita & $17 / 47(36)$ & 2/17 (12) \\
\hline Rodentia-Cricetidae & Akodon sp. & $3 / 20(15)$ & $0 / 3$ \\
\hline Rodentia-Cricetidae & Nectomys squamipes & 15/18 (83) & $0 / 15$ \\
\hline Rodentia-Cricetidae & Oryzomys sp. & $0 / 2$ & $0 / 0$ \\
\hline Rodentia-Echimydae & Trynomys sp. & $0 / 1$ & $0 / 0$ \\
\hline Total & - & $35 / 88(40)$ & 2/35 (6) \\
\hline
\end{tabular}

HC: haemoculture; IFAT: indirect fluorescent antibody test.

\section{TABLE II}

Follow-up of Trypanosoma cruzi infection in the free-ranging populations of Leontopithecus rosalia (golden lion tamarin) and Leontopithecus chrysomelas (golden-headed lion tamarin) from Southeast Atlantic Coastal Rainforest of Brazil (1995-2005)

\begin{tabular}{lcccc}
\hline Species & Studies & $\begin{array}{c}\text { Positive IFAT/ } \\
\text { examined tamarins } \\
\text { areas }\end{array}$ & $\begin{array}{c}\text { Positive HC/ }(\%) \\
\text { positive IFAT } \\
\mathrm{n} / \mathrm{n}(\%)\end{array}$ & $\begin{array}{c}\text { Serological conversion/ } \\
\text { tamarins tested } \\
\mathrm{n} / \mathrm{n}(\%)\end{array}$ \\
\hline Leontopithecus rosalia & $\mathrm{PDA}$ & $140 / 249(56)$ & $95 / 140(68)$ & $35 / 107(33)$ \\
& $\mathrm{RA}^{a}$ & $8 / 54(11)$ & $8 / 8(100)$ & $1 / 6(17)$ \\
Leontopithecus chrysomelas & $\mathrm{UNA}$ & $58 / 76(76)$ & $39 / 58(65)$ & $19 / 34(56)$ \\
\hline
\end{tabular}

$a$ : includes 21 privately owned farms; HC: haemoculture; IFAT: indirect fluorescent antibody test; PDA: Poço das Antas Biological Reserve [municipality of Silva Jardim, state of Rio de Janeiro (RJ)]; RA: reintroduction areas [municipalities of Rio Bonito, Silva Jardim and Casimiro de Abreu (RJ)]; UNA: Una Biological Reserve (municipality of Una, state of Bahia).

T. cruzi infection follow-up of golden and goldenheaded lion tamarins between 1995-2005 - Both tamarin species demonstrated their ability to maintain a stable and well-established T. cruzi (DTU TcII) transmission cycle in two geographical regions of the Atlantic Coastal Rainforest, based on their the high parasitological and serological T. cruzi infection prevalence. During the 11year-long study, we also observed a high serum conversion rate in golden and golden-headed lion tamarins as indicated in Table II. As far as we know, this is the most stable and expressive transmission cycle of $T$. cruzi II ever observed in a wild environment. Moreover, herein we are demonstrating that in addition to TcII, nine tamarins maintained long-lasting infections by DTU TcI, as confirmed with recaptured and retested primates.

The prevalence of positivity for the parasitological and serological tests with the golden lion tamarin populations exhibited fluctuation with a peak prevalence every three years (Fig. 2).

Modification of the T. cruzi infection in golden lion tamarins was also observed. Thus, in two RA (Santa

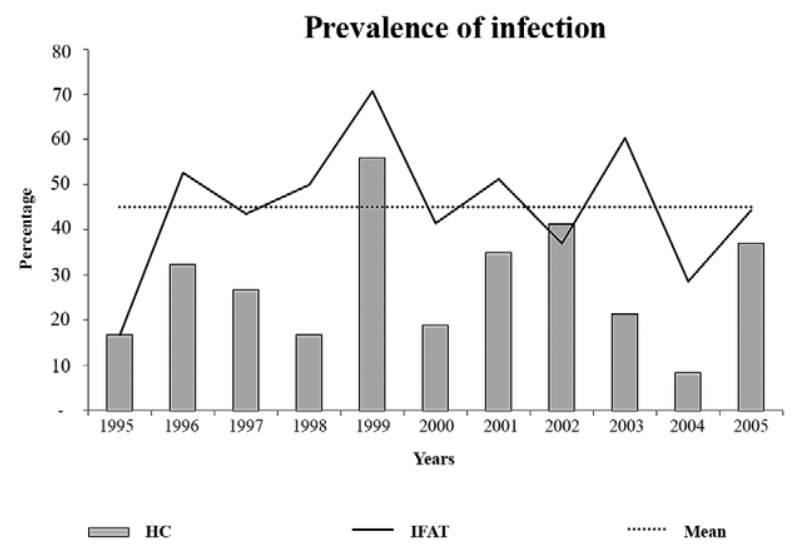

Fig. 2: graphical representation of the peaks in the annual prevalence of infection according to indirect fluorescent antibody test (IFAT) and haemoculture (HC) in wild free-ranging populations of golden lion tamarin (Leontopithecus rosalia) from Poço das Antas Biological Reserve, municipality of Silva Jardim, state of Rio de Janeiro, Brazil. 


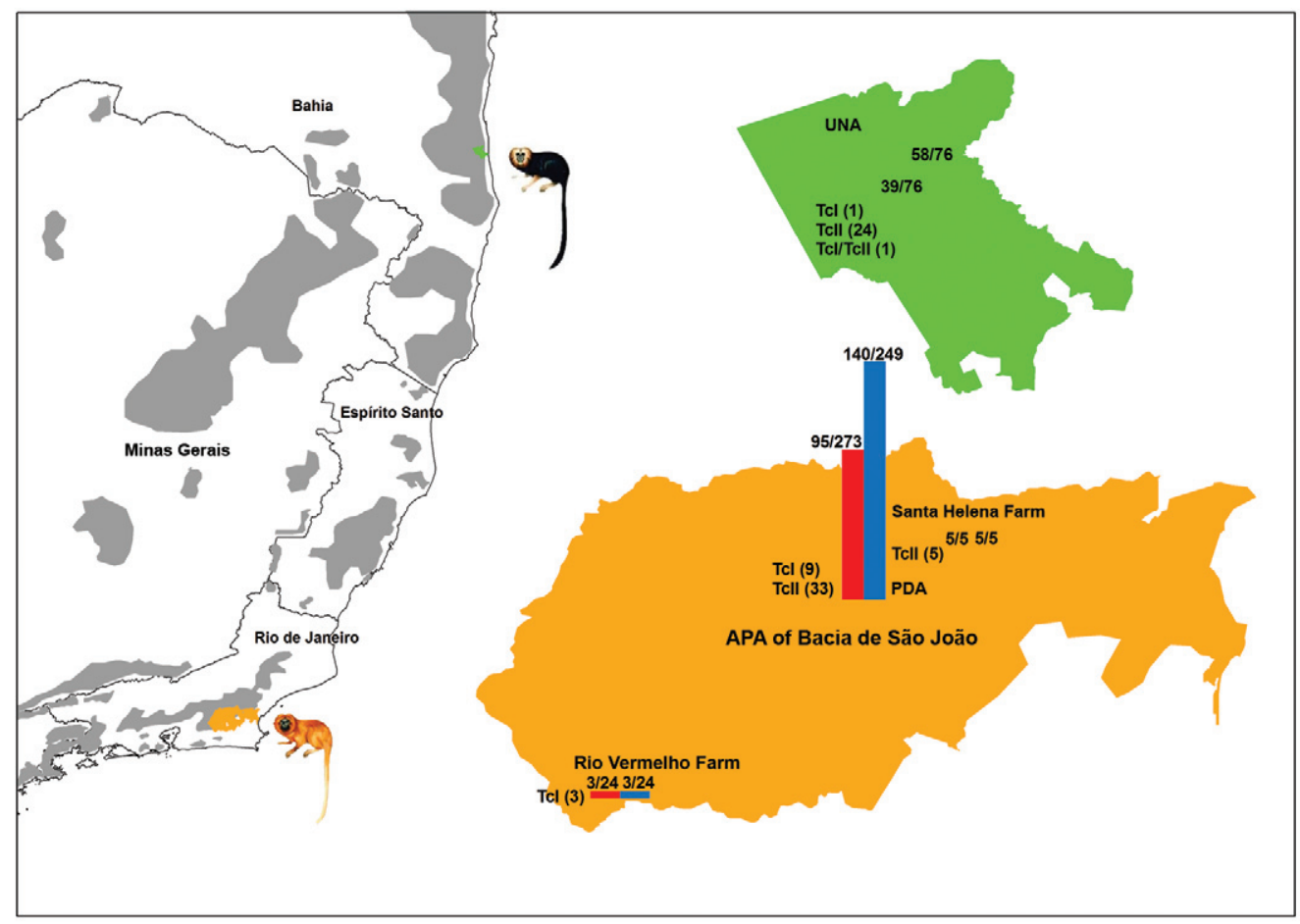

Fig. 3: Trypanosoma cruzi discrete typing unit of wild free-ranging Leontopithecus rosalia (golden lion tamarin) and Leontopithecus chrysomelas (golden-headed lion tamarin) from Atlantic Coastal Rainforest, Brazil.

Helena Farm and Rio Vermelho Farm) where the $T$. cruzi infection of the animals was always subpatent and only detectable by serology, eight animals displayed positive blood cultures, ie., high infective competence during our last year of our study.

Overall infection rates differed in the distinct social groups of both tamarin species. Thus, it was possible to observe three infection patterns according to social group: (i) groups in which the individuals never seroconverted, i.e., never became infected during followup, (ii) groups in which the individuals seroconverted and had positive $\mathrm{HC}$ or had only positive serological tests (IFAT), and (iii) individuals that exhibited high rates of positive IFAT and $\mathrm{HC}$ tests.

The absence of trypomastigotes in the peripheral blood was a common trait in all infected animals.

Molecular characterised of 77 T. cruzi isolates - RA - Three golden lion tamarins isolates from Rio Vermelho Farm were characterised as TcI, while five golden lion tamarins isolates from Santa Helena Farm exhibited the TcII profile (Fig. 3).

$P D A$ - Molecular analysis permitted the confirmation of DTU TcII (TcIlb) for 33 out of 42 tamarins formerly typed (mini-exon gene) as TcII (Lisboa et al. 2004). Moreover, nine golden lion tamarin isolates that originally tested as TcII (Fernandes et al. 1998) were shown to be DTU TcI (Fig. 3).

UNA - In the UNA, the mini-exon gene characterisation of 24 golden-headed lion tamarins isolates resulted in a TcII profile, while one tamarin isolate corresponded to TcI and another was demonstrated to be a mixed infection by TcI and TcII. Analyses by $24 \mathrm{~S} \alpha$ rDNA and PCR-RFLP with HSP60 and GPI markers confirmed the mini-exon genotyping (Fig. 3).

\section{DISCUSSION}

The majority of epidemiological studies are based on one single report of animal infection prevalence and without regard for ecological variables involved in the analysed ecosystem that certainly influence the dynamics of a multi-host-parasite system. Indeed, long-lasting studies of T. cruzi transmission among free-ranging sylvatic primates species are scarce, as they necessitate significant financial support, skilled personnel, long studies about the social behaviours of primates and a multidisciplinary team.

In Brazil, natural infection by T. cruzi has been reported in primates included in the following families: Cebidae (capuchins, tamarins, marmosets and squirrel monkeys), Nyctipithecidae (night monkeys), Pitheciidae (sakis and uakaris) and Atelidae (spider monkeys and howler monkeys) (Ziccardi et al. 2000, Lisboa et al. 2006, da Silva et al. 2008).

The prevalence of $T$. cruzi infection in endemic primates from Amazon ranged from $10.3 \%$ using parasitological methods (blood smear microscopy, HC and xenodiagnosis) (Ziccardi \& Lourenço-de-Oliveira 1997, Ziccardi et al. 2000 ) to $46 \%$ detected by serology, i.e., IFAT (Lisboa et al. 2006). No studies of the T. cruzi infection in primates have been conducted in the other Brazilian biomes. 
Regarding the molecular identification of $T$. cruzi isolates obtained from primates in the Amazon Region only TcI and/or TcIV have been observed (Miles et al. 1981, da Silva et al. 2008, Marcili et al. 2009, Hamilton et al. 2011).

The assemblage of our data showed that a stable transmission cycle of DTU TcII was efficiently maintained in the wild environment by a free-ranging golden lion tamarin's population for at least for 11 years (Fig. 4). Additionally, T. cruzi serum conversion (> 51\%) and HC positivity of originally noninfected, re-examined tamarins demonstrated active transmission occurring throughout our 11-year long follow-up period. This enzootic scenario confirms a very well established and robust sylvatic transmission cycle of TcII, a DTU previously associated with human infection, in the Atlantic Forest.

The reproductive strategy of mammals $(\mathrm{K} / \mathrm{r})$ apparently does not influences $T$. cruzi reservoir competence in its different mammal host species as long-lived mammalian species (such as lion tamarins and coatis) and short-lived (such as opossums and rodents) may maintain high and long-lasting parasitaemias, being excellent sources of transmission as attested by the high rates of positive T. cruzi HCs observed in infected exemplars (MacArthur \& Wilson 1967, Lisboa et al. 2006, BottoMahan et al. 2010, Alves et al. 2011).

A very interesting aspect was the wave-like profiles of the infective competence of the T. cruzi-infected tamarin populations that cannot be explained be serial reinfection, as experimentally infected mammals do not again exhibit an increase in parasitaemia upon re-infection (Machado et al. 2001, Andrade et al. 2006, Añez et al. 2011). However, climatic or seasonal events may explain, at least partially, peaks in parasitaemia among vulnerable mammalian species. Interestingly, the high parasitaemia peak of the golden lion tamarin population occurred in 1999 soon after the severe ENSO event in 1997-1998 (Lima et al. 2003). The same climatic event affected the prevalence of T. cruzi infection in Octodon degus from Chile, where the highest peaks of infectivity were observed in the years 1999-2000 (Previtali et al. 2009, Botto-Mahan et al. 2012). Overall, it has already been proposed that enhanced vector-borne and specifically $T$. cruzi transmission correlated to El Niño events (Chaves \& Pascual 2006, Keesing et al. 2006, Chaves et al. 2008, Zaraket et al. 2008, Mantilla et al. 2009, Botto-Mahan et al. 2010). Seasonal influence has been described to modulate reservoir competence for T. cruzi in Nasua nasua, which exhibits higher parasitaemia during the dry season in the region of Pantanal (Alves et al. 2011).

Our results suggested that vertical transmission does not occur, i.e., infected females do not transmit the parasite to the newborns, which are born free of $T$. cruzi infection, as demonstrated by 11 offspring of infected females that were not infected by the parasite, as determined by $\mathrm{HC}$ and IFAT as previously described in Lisboa et al. $(2000,2004)$. More details related to the age, gender and reproductive status of golden lion tamarins and $T$. cruzi infection can be found in Lisboa et al. $(2000,2004)$.

Two nonexclusive hypotheses may explain why certain golden lion tamarins did not acquire infection (dur-

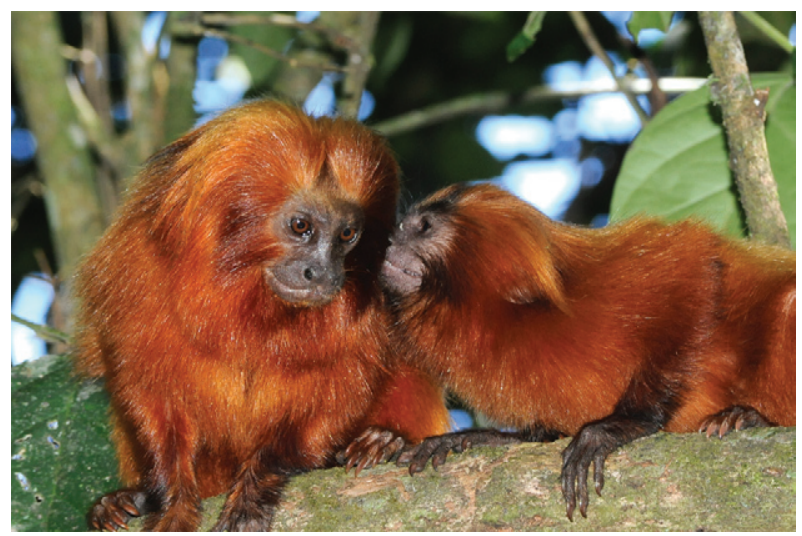

Figure 4: the golden lion tamarin (Leontopithecus rosalia) of Poço das Antas Biological Reserve, municipality of Silva Jardim, state of Rio de Janeiro, Brazil. Photo by Rodrigo Méxas (Oswaldo Cruz Institute/Oswaldo Cruz Foundation).

ing our follow-up) and other golden lion tamarins became infected soon after weaning (Lisboa et al. 2004), even in the same social group: (i) microenvironmental differences, which result in cumulative distribution of triatomines and/or (ii) individual behavioural characteristics due to different roles played within the social group. Risk of exposure to infection may also be associated with aggressiveness and boldness that lead to agonistic encounters (Kortet \& Hedrick 2007, Kortet et al. 2010). Dominance status in social animals may affect both exposure to parasites and immune functions, as dominant individuals have better access to food resources than subordinate individuals (Stahl et al. 2001). Our data are partially in agreement with these studies. In fact both dominants and subordinates golden lion tamarins were infected with T. cruzi. Moreover and very important, all noninfected golden lion tamarins belonged to the subordinate class, suggesting at least a tendency towards reduced exposure to $T$. cruzi infection for less aggressive individuals. Individual variation in parasitaemia as expressed by positive or negative HCs is well known in other model hosts, including under laboratory conditions and is probably the consequence of individual differences in nutritional or energetic state, which can have strong effect on the host response to parasites (Michael \& Bundy 1992, Chandra 2002, Demas 2004, Houston \& McNamara 2013). An environmental or behavioural difference as explanation for these differences is reinforced by the homogeneity of the genetic background of both the parasite and the hosts. The golden-headed lion tamarin from UNA can also be considered an amplifier host of $T$. cruzi infection. Moreover, we could not forecast the evolution of $T$. cruzi infection patterns in golden-headed lion tamarin. Indeed, for two species of Didelphiomorphia, D. aurita and Philander frenata, that were observed to have high positive HCs of T. cruzi in 1995 in the city of Teresópolis (Atlantic Forest of altitude), no positive HCs were detected 10 years later in serologically positive marsupials (Pinho et al. 2000, Vaz et al. 2007). 
DTU TcII was exclusively found in primates; no other mammal species infected with TcII in the PDA were observed. This may be partially explained by the absence of exposure of these mammals to this $T$. cruzi DTU or by their death due to infection. The nine isolates of golden lion tamarins, which were demonstrated to be DTU TcI based on the second molecular characterisation (PCR-RFLP), suggested that these animals were infected with both subpopulations (TcI and TcII). Thus, selective forces during the first amplification procedures of these isolates selected only the TcII subpopulation instead of both TcII and TcI. It is likely that infection by TcI result in low parasitaemia in golden lion tamarin; therefore, the parasite cannot be isolated by blood culture due to the low sensibility of the method. Golden lion tamarin sera samples that do not test positive for blood culture eventually may be positive for TcI. The occurrence of the golden lion tamarins infected with both TcI and TcII in PDA shows that the transmission cycles of both $T$. cruzi DTUs occur sympatrically in almost independent ways.

The change of enzootic scenery observed in two RA confirms the dynamic character of transmission cycles; thus, both $T$. cruzi DTUs (TcI and TcII) may coexist in the same RA forest fragment, in this context, TcI infected only D. aurita and TcII infected golden lion tamarins. Wild rodents demonstrated to be infected by $T$. cruzi with low reservoir competence, as positive blood cultures were not observed.

Investigation of the triatomine fauna in the studied areas was performed by actively searching in hollow trees, bird and opossum nests and armadillo hollows, in addition to use the spray Pirisa 1080-L1 and light traps. However, we captured only two triatomines vectors: Triatoma vitticeps and Panstrongylus megistus, respectively. Both were infected with the same genotype of lion tamarin, TcII, demonstrating that these species were involved in the sylvatic transmission cycle of $T$. cruzi in wild population of golden lion tamarins. These data have been presented and discussed elsewhere (Lisboa et al. 2000, 2004).

The infection of tamarins may have occurred due to presence of the triatomine in the tamarin sleeping sites (hollow tree cavities, bamboo thickets, dense vine, palm crowns) as suggested by Lisboa et al. (2004). Another possibility is the infection by the oral route, which is the main route of infection in a wild environment, as bromeliads and palms, which are triatomine habitats, are also frequently used by golden lion tamarin in search for animal prey. It is worth remembering that the vegetation typical of the Atlantic Rainforest is rich in palms, mostly Astrocaryum spp and Attalea spp (Pires \& Fernandez 1999), which are palm species associated with the presence of triatomines.

It is very likely that these endemic primates of the Atlantic Rainforest had already been exposed to TcII (and TcI) long before the creation of the PDA (1974) and/or UNA (1980) in a continuous strip of Atlantic Forest before the fragmentation process. The six DTU of $T$. cruzi apparently display different strategies for their maintenance and dispersion in nature; thus, one can assume that TcII is a successful T. cruzi subpopulation. Indeed, this genotype may be found dispersed on almost all Brazil- ian biomes, infecting several mammalian taxa, as already mentioned, and establishing a peculiar interaction with each host species. Thus, four-eyed opossums (P. frenata), coatis, but principally lion tamarins may maintain high parasitaemias by this genotype as evidenced by high rates of recovery of the parasite in HC. Wild and domestic Canidae exhibit only a short period of high infectivity (Rocha et al. 2013). Considering that all these animal species are included in a trophic network, transmission will be enhanced or diminished according to local mammalian faunal composition. Finally, the data presented herein point to the necessity for long-term studies of host-parasite interactions if a solid knowledge of the ecology of a given parasite species is desired. All together, the data also indicates how far we still are from understanding the dispersal strategies of each T. cruzi DTU ecology.

\section{ACKNOWLEDGEMENTS}

To Vera Bongertz, for her critical reading and revision of the paper, to all workers from PDA/ICMBio office, to the Golden Lion Tamarim Conservation Program, to Rodrigo Mexas, for design support and photographs, and to Samanta Cristina das Chagas Xavier, for map preparation.

\section{REFERENCES}

Alves FM, Olifiers N, Bianchi RC, Duarte AC, Cotias PM 2011. Modulating variables of Trypanosoma cruzi and Trypanosoma evansi transmission in free-ranging coati (Nasua nasua) from the Brazilian Pantanal region. Vector Borne Zoonotic Dis 1: 835-841.

Andrade SG, Campos RF, Sobral KSC, Magalhães JB, Guedes RSP, Guerreiro ML 2006. Reinfections with strains of Trypanosoma cruzi of different biodemes as a factor of aggravation of myocarditis and myositis in mice. Rev Soc Bras Med Trop 39: 1-8.

Añez N, Crisante G, Caraballo F, Delgado W, Parada H 2011. Trypanosoma cruzi persistence at oral inflammatory foci in chronic chagasic patients. Acta Trop 117: 207-211.

Ashford RW 1996. Leishmaniasis reservoirs and their significance in control. Clin Dermatol 14: 523-532.

Beck B, Kleiman D, Dietz J, Castro I, Carvalho C, Martins A, Rettberg-Beck B 1991. Losses and reproduction in reintroduced golden lion tamarins. JWPT 27: 50-61.

Botto-Mahan C, Bacigalupo A, Correa JP, Oda E, Solari A 2012. Field assessment of Trypanosoma cruzi infection and host survival in the native rodent Octodon degus. Acta Trop 122: 164-167.

Botto-Mahan C, Campos R, Acunã-Retamar M, Coronado X 2010. Temporal variation of Trypanosoma cruzi infection in native mammals in Chile. Vector Borne Zoonotic Dis 10: 317-319.

Brisse S, Barnabé C, Tibayrenc M 2001. Characterisation of large and small subunit rRNA and mini-exon genes further supports the distinction of six Trypanosoma cruzi lineages. Int J Parasitol 31: 1218-1226.

Camargo ME 1966. Fluorescent antibody test for the serodiagnosis of American trypanosomiasis. Technical modification employing preserved culture forms of Trypanosoma cruzi in a slide test. Rev Soc Bras Med Trop 8: 227-235.

Chandra RK 2002. Nutrition and the immune system from birth to old age. Eur J Clin Nutr 56 (Suppl. 3): 73-76.

Chaves L, Pascual M 2006. Climate cycles and forecasts of cutaneous leishmaniasis, a non-stationary vector borne disease. PLoS Med 3: e295. 
Chaves LF, Cohen JM, Pascual M, Wilson ML 2008. Social exclusion modifies climate and deforestation impacts on a vector-borne disease. PLoS Negl Trop Dis 2: e176.

da Silva FM, Naiff RD, Marcili A, Gordo M, D’Affonseca Neto JA, Naiff MF, Franco AM, Campaner M, Valente V, Valente SA, Camargo EP, Teixeira MM, Miles MA 2008. Infection rates and genotypes of Trypanosoma rangeli and T. cruzi infecting freeranging Saguinus bicolor (Callitrichidae), a critically endangered primate of the Amazon Rainforest. Acta Trop 107: 168-173.

Demas GE 2004. The energetics of immunity: a neuroendocrine link between energy balance and immune function. Horm Behav 45: $173-180$

Fernandes O, Mangia RH, Lisboa CV, Pinho AP, Morel CM, Zingales B, Campbell D, Jansen AM 1998. The complexity of the sylvatic cycle of Trypanosoma cruzi in the Rio de Janeiro state (Brazil) revealed by the non-transcribed spacer of the min-exon gene. Parasitology 118: 161-166.

Fernandes O, Santos SS, Cupolillo E, Mendonça B, Derre R, Junqueira AC 2001. A mini-exon multiplex polymerase chain reaction to distinguish the major groups of Trypanosoma cruzi and T. rangeli in the Brazilian Amazon. Trans R Soc Trop Med Hyg 95: 97-99.

Franke CR, Ziller M, Staubach C, Latif M 2002. Impact of the El Niño Southern Oscillation on visceral leishmaniasis, Brazil. Emerg Infect Dis 8: 914-917.

Hamilton PB, Lewis MD, Cruickshank C, Gaunt MW, Yeo M, Llewellyn MS, Valente SA, da Silva FM, Stevens JR, Miles MA, Teixeira MM 2011. Identification and lineage genotyping of South American trypanosomes using fluorescent fragment length barcoding. Infect Genet Evol 11: 44-51.

Herrera HM, Lisboa CV, Pinho AP, Olifiers N, Bianchi RC, Rocha FL, Mourão GM, Jansen AM 2008. The coati (Nasua nasua, Carnivora, Procyonidae) as a reservoir host for the main lineages of Trypanosoma cruzi in the Pantanal region, Brazil. Trans $R$ Soc Trop Med Hyg 102: 133-139.

Herrera L, D'Andrea PS, Xavier SC, Mangia RH, Fernandes O, Jansen AM 2005. Trypanosoma cruzi infection in wild mammals of the National Park Serra da Capivara and its surroundings (Piauí, Brazil), an area endemic for Chagas disease. Trans R Soc Trop Med Hyg 99: 379-388.

Houston AI, McNamara JM 2013. Foraging currencies, metabolism and behavioural routines. J Anim Ecol 83: 30-40.

Keesing F, Holt RD, Ostfeld RS 2006. Effects of species diversity on disease risk. Ecol Lett 9: 485-498.

Kortet R, Hedrick A 2007. A behavioural syndrome in the field cricket Gryllus integer: intrasexual aggression is correlated with activity in a novel environment. Biol J Linn Soc Lond 91: 475-482.

Kortet R, Hedrick A, Vainikka A 2010. Parasitism, predation and the evolution of animal personalities. Ecol Lett 13: 1449-1458.

Lewis MD, Ma J, Yeo M, Carrasco HJ, Llewellyn MS, Miles MA 2009. Genotyping of Trypanosoma cruzi: systematic selection of assays allowing rapid and accurate discrimination of all known lineages. Am J Trop Med Hyg 8: 1041-1049.

Lima M, Stenseth NC, Leirs H, Jaksic FM 2003. Population dynamics of small mammals in semiarid regions: a comparative study of within-year demographic variability in two rodent species. Proc R Soc Lond B Biol Sci 270: 1997-2007.

Lisboa CV, Dietz J, Baker AJ, Russel NN, Jansen AM 2000. Trypanosoma cruzi infection in Leontopithecus rosalia at the Reserva
Biológica de Poço das Antas, Rio de Janeiro, Brazil. Mem Inst Oswaldo Cruz 95: 445-452.

Lisboa CV, Mangia RH, de Lima NR, Martins A, Dietz J, Baker AJ, Ruiz-Miranda CR, Ferreira LF, Fernandes O, Jansen AM 2004. Distinct patterns of Trypanosoma cruzi infection in Leontopithecus rosalia in distinct Atlantic Coastal Rainforest fragments in Rio de Janeiro, Brazil. Parasitology 129: 703-711.

Lisboa CV, Mangia RH, Luz SL, Kluczkovski Jr A, Ferreira LF, Ribeiro CT, Fernandes O, Jansen AM 2006. Stable infection of primates with Trypanosoma cruzi I and II. Parasitology 133: 603-611.

Lisboa CV, Pinho AP, Herrera HM, Gerhardt M, Cupolillo E, Jansen AM 2008. Trypanosoma cruzi (Kinetoplastida, Trypanosomatidae) genotypes in Neotropical bats in Brazil. Vet Parasitol 156: 314-318.

Lisboa CV, Xavier SC, Herrera HM, Jansen AM 2009. The ecology of the Trypanosoma cruzi transmission cycle: dispersion of zymodeme 3 (Z3) in wild hosts from Brazilian biomes. Vet Parasitol 165: 19-24.

MacArthur R, Wilson EO 1967. The theory of island biogeography, Princeton University Press, Princeton, 580 pp.

Machado EM, Fernandes AJ, Murta SM, Vitor RW, Camilo Jr DJ, Pinheiro SW, Lopes ER, Adad SJ, Romanha AJ, Dias JP 2001. A study of experimental reinfection by Trypanosoma cruzi in dogs. Am J Trop Med Hyg 65: 958-965.

Mantilla G, Oliveros H, Barnston AG 2009. The role of ENSO in understanding changes in Colombia's annual malaria burden by region, 1960-2006. Malar J 8: 6.

Marcili A, Lima L, Cavazzana MJ, Junqueira ACV, Veludo HH, da Silva FM, Campaner M, Paiva F, Nunes VLB, Teixeira MMG 2009. A new genotype of Trypanosoma cruzi associated with bats evidenced by phylogenetic analyses using SSU rDNA, cytochrome $\mathrm{b}$ and histone H2B genes and genotyping based on ITS1 rDNA. Parasitology 136: 641-655.

McMichael AJ 2003. Global climate change: will it affect vectorborne infectious diseases? Intern Med J 33: 554-555.

Michael E, Bundy DAP 1992. Protein-content of cba/ca mouse dietrelationship with host antibody-responses and the populationdynamics of Trichuris muris (Nematoda) in repeated infection. Parasitology 105: 139-150.

Miles MA, Llewellyn MS, Lewis MD, Yeo M, Baleela R, Fitzpatrick S, Gaunt MW, Mauricio IL 2009. The molecular epidemiology and phylogeography of Trypanosoma cruzi and parallel research on Leishmania: looking back and to the future. Parasitology 136: 1509-1528.

Miles MA, Povoa MM, de Souza AA, Lainson R, Shaw JJ, Ketteridge DS 1981. Chagas disease in the Amazon Basin. II. Distribution of Trypanosoma cruzi zymodemes 1 and 3 in Pará state, North Brazil. Trans R Soc Trop Med Hyg 75: 667-674.

Monteiro RV, Dietz JM, Beck BB, Baker AJ, Martins A, Jansen AM 2007. Prevalence and intensity of intestinal helminths found in free-ranging golden lion tamarins (Leontopithecus rosalia, Primates, Callitrichidae) from Brazilian Atlantic Forest. Vet Parasitol 145: 77-85.

Monteiro RV, Dietz JM, Jansen A 2010. The impact of concomitant infections by Trypanosoma cruzi and intestinal helminths on the health of wild golden and golden-headed lion tamarins. Res Vet Sci 89: 27-35.

Pinho AP, Cupolillo E, Mangia RH, Fernandes O, Jansen AM 2000. Trypanosoma cruzi in the sylvatic environment: distinct transmission cycles involving two sympatric marsupials. Trans $R$ Soc Trop Med Hyg 94: 509-514. 
Pires AS, Fernandez FAS 1999. Use of space by the marsupial Micoreus demerarae in small Atlantic Forest fragments in southeastern Brazil. J Trop Ecol 15: 279-290.

Previtali MA, Meserve PL, Kelt DA, Milstead WB, Gutierrez JR 2009. Effects of more frequent and prolonged El Niño events on life-history parameters of the Degus, a long-lived and slow-reproducing rodent. Conserv Biol 24: 18-28.

Ramírez JD, Montilla M, Cucunubá ZM, Floréz AC, Zambrano P, Guhl F 2013. Molecular epidemiology of human oral Chagas disease outbreaks in Colombia. PLoS Negl Trop Dis 7: e2041.

Rocha FL, Roque AL, de Lima JS, Cheida CC, Lemos FG, de Azevedo FC, Arrais RC, Bilac D, Herrera HM, Mourão G, Jansen AM 2013. Trypanosoma cruzi infection in Neotropical wild carnivores (Mammalia: Carnivora): at the top of the T. cruzi transmission chain. PLOS ONE 8: e67463.

Roque AL, Xavier SC, da Rocha MG, Duarte AC, D'Andrea OS, Jansen AM 2008. Trypanosoma cruzi transmission cycle among wild and domestic mammals in three areas of orally transmitted Chagas disease outbreaks. Am J Trop Med Hyg 79: 742-749.

Rozas M, de Doncker S, Adaui V, Coronado X, Barnabé C, Tibyarenc M, Solari A, Dujardin JC 2007. Multilocus polymerase chain reaction restriction fragment-length polymorphism genotyping of Trypanosoma cruzi (Chagas disease): taxonomic and clinical applications. J Infect Dis 195: 1381-1388.
Sambrook J, Fritsch E, Maniatis T 1989. Molecular cloning. A laboratory manual, Cold Spring Harbor Laboratory Press, New York, 1626 pp.

Stahl J, Tolsma PH, Loonen MJ, Drent RH 2001. Subordinates explore but dominants profit: resource competition in high Arctic barnacle goose flocks. Anim Behav 61: 257-264.

Vaz VC, D'Andrea PS, Jansen AM 2007. Effects of habitat fragmentation on wild mammal infection by Trypanosoma cruzi. Parasitology 134: 1785-1793.

Zaraket H, Saito R, Tanabe N, Taniguchi K, Suzuki H 2008. Association of early annual peak influenza activity with El Niño Southern Oscillation in Japan. Influenza Other Respir Viruses 2: 127-130.

Ziccardi M, Lourenço-de-Oliveira R 1997. The infection rates of trypanosomes in squirrel monkeys at two sites in the Brazilian Amazon. Mem Inst Oswaldo Cruz 92: 465-470

Ziccardi M, Lourenço-de-Oliveira R, Lainson R, Brígido MCO, Muniz JAPC 2000. Trypanosomes of non-human primates from the National Centre of Primates, Ananindeua, state of Pará, Brazil. Mem Inst Oswaldo Cruz 95: 157-159.

Zingales B, Miles MA, Campbell DA, Tibayrenc M, Macedo AM, Teixeira MM, Schijman AG, Llewellyn MS, Lages-Silva E, Machado CR, Andrade SG, Sturm NR 2012. The revised Trypanosoma cruzi subspecific nomenclature: rationale, epidemiological relevance and research applications. Infect Genet Evol 12: 240-253. 